\title{
sciendo
}

Int. J. of Applied Mechanics and Engineering, 2020, vol.25, No.2, pp.103-121

DOI: $10.2478 /$ ijame-2020-0023

\section{INFLUENCE OF CHEMICAL REACTION ON THE HEAT AND MASS TRANSFER OF NANOFLUID FLOW OVER A NONLINEAR STRETCHING SHEET: A NUMERICAL STUDY}

\author{
SANTOSHI MISRA* \\ Department of Mathematics, St. Ann's College for Women \\ Mehdipatnam, Hyderabad, Telangana, INDIA \\ E-mail: sonyshukla29@gmail.com \\ K. GOVARDHAN \\ Department of Mathematics, GITAM University Hyderabad \\ INDIA
}

\begin{abstract}
A numerical study on a steady, laminar, boundary layer flow of a nanofluid with the influence of chemical reaction resulting in the heat and mass transfer variation is made. The non-linear governing equations with related boundary conditions are solved using Adam's predictor corrector method with the effect of a Brownian motion and thermophoresis being incorporated as a model for the nanofluid, using similarity transformations. Validation of the current numerical results has been made in comparison to the existing results in the absence of chemical reaction on MHD flows. The numerical solutions obtained for the velocity, temperature and concentration profiles for the choice of various parameters are represented graphically. Variations of heat and mass transfer across a Brownian motion and thermophoresis are studied and analyzed.
\end{abstract}

Key words: nanofluid, Brownian motion, thermophoresis, chemical reaction, heat transfer, mass transfer.

\section{Introduction}

The study of problems involving Magneto Hydro Dynamic (MHD) boundary layer flow and behavior over a stretching sheet have been the motive and focus of research, due to its widespread applications in the field of engineering, science and technology. To name a few: materials manufactured by extrusion, glass fiber, paper production, wiredrawing, metal spinning, hot rolling etc. are a few significant applications. Analysis of the boundary layer involving two dimensional flows was initially developed by Sakiadis [1]. It gained immense popularity among young researchers due to its extension in distinct areas of Industrial and applied science. Crane [2] studied the Navier Stokes equations for the conservation of mass and momentum which was further investigated by Anderson [3] on viscous flows using finite difference methods.

Recently, problems involving flow and heat transfer of nanofluids have gained popularity due to their novel properties and enhanced thermal conductivity, convective heat transfer coefficient in comparison to base fluids like water, ethylene, glycol, oil, etc. Nanofluids contain nano-meter sized particles below $100 \mathrm{~nm}$ in at least one dimension possessing uniformity, conductance and magnifying properties making it easier to use them in fields involving medicine, science, consumer goods, etc. with the primary focus on refining the environment for ameliorating human life.

On par with previous findings, Hayat and Waqas [4], Rana and Bhargava [5] explored the area involving boundary layer flow of nanofluids due to their enhanced heat and mass transfer properties using several intensifying methods to solve the Navier Stokes equations. The behavior of heat and mass transfer rates under the influence of different dimensionless parameters over a Maxwell fluid was studied by Hayat. Sheikholeslami [6] studied the magnetic field effect in MHD flows using an effective numerical method called the control volume based finite element method to examine the influence of various parameters on

\footnotetext{
* To whom correspondence should be addressed
} 
thermal boundary layer and fluid flow. Hayat et al. [7] carried out the modelling and analysis of Burgers' nanofluids with the magnetic field influence of nano particles for various dimensionless parameters effecting the heat transfer. Waqas et al. [8] dealt with micro polar liquids in nonlinear surface for magneto hydrodynamic flows where the skin friction coefficient and local Nusselt number were evaluated under the effect of external fields. Hayat et al. [9] analysed heat and mass transfer rates of a third grade fluid flow subjected to a stretching surface under the external parameters involving first order chemical reaction. Hayat et al. [10] explored the flow of an Oldroyd-B liquid under the influence of first order chemical reaction with linear surface for the variations in temperature, velocity and nanoparticle concentrations. Hayat et al. [11] studied the flow of a Maxwell nanofluid in an unsteady state with nonlinear equations for the heat transfer rate. An Oldroyd B-fluid is taken into account to study the stagnation flow for an unsteady boundary value problem by Hayat et al. [12]. The study was further extended by Hayat et al. [13] who discussed the case of the tangent hyperbolic nanofluid flow with magnetic particles influencing the heat and mass transfer rates with regard to the temperature and concentration of nanoparticles.

The nonlinear boundary value problem with variable thickness under the influence of chemical reaction using the non Fourier heat flux model was addressed by Hayat et al. [14]. Due to high thermal conductivity and various novel properties of carbon nanotubes, Hayat et al. [15] studied the importance of Darcy-Forchheimermodel in single and multi walled carbon nanotubes for velocity, temperature and skin friction distributions. Asghar et al. [16] investigated the heat transfer rates through a porous medium using Sisko fluids in biological systems for enhanced values of velocity in comparison to other models. A mathematical modelling for a Jeffrey nanofluid flow using heat generation and absorption coefficient to study the thermal radiation was carried out by Waqas et al. [17]. The non-linear study of nanofluids was elaborated using ferroliquids by Waqaset al. [18]. Waqas et al. [19] extended the carbon nanotube study using the Von Karman approach. Waqas [20] investigated the heat transfer flow in a ferromagnetic system considering a nonNewtonian fluid with chemical reactions to study the velocity and temperature gradients of the fluid under the influence of dimensionless parameters. Waqas et al. [21], Dogonchiet al. [22], Farooq et al. [23] carried out substantial investigations to scrutinize the heat and mass transfer effects including the study of velocity, thermal radiation and nanoparticle concentrations useful to enhance varied real time applications.

With regard to the findings and investigations carried out by various researchers, the objective of the present work is to study a steady boundary layer flow with a nonlinear stretching sheet. An effective Adam's predictor corrector method has been employed using FORTRAN programming to study the influence of the Brownian motion, thermophoresis stretching parameter, Lewis number on temperature and concentration distribution of the fluid flow. Apart from this, the impact of chemical reaction on dimensionless temperature, dimensionless concentration, variation of heat transfer $\left(-\theta^{\prime}(0)\right)$ and mass transfer $\left(-\phi^{\prime}(0)\right)$ with thermophoresis and Brownian motion parameters in the presence of chemical reaction has been analyzed and a detailed description has been presented graphically. Applications involving the heat and mass transfer effect in the presence of chemical reaction can attract interest of researchers.

\section{Problem formulation}

We consider a two-dimensional steady, incompressible laminar MHD boundary layer flow of a nanofluid immersed in a base fluid comprising water, where the flow is generated past a nonlinear stretching surface, over a flat sheet coinciding with the plane $y=0$, as shown in Fig.1, where $u_{w}(x)=a x^{n}$ is the velocity of the sheet, with origin being fixed, $n$ is the stretching parameter, ' $a$ ' is the constant, ' $x$ ' is the coordinate along the stretching surface. $T_{w}, C_{w}$ represent the wall temperature, nanoparticle fractions which are constant across the stretching surface, where the pressure acting and external forces are neglected. $T_{w}, C_{w}$ are assumed to be greater than the ambient temperature and nanoparticle fractions $T_{\infty}, C_{\infty}$ respectively, for the physical model setup, which has been applied in modern nanotechnology and thermal manufacturing in various companies. 


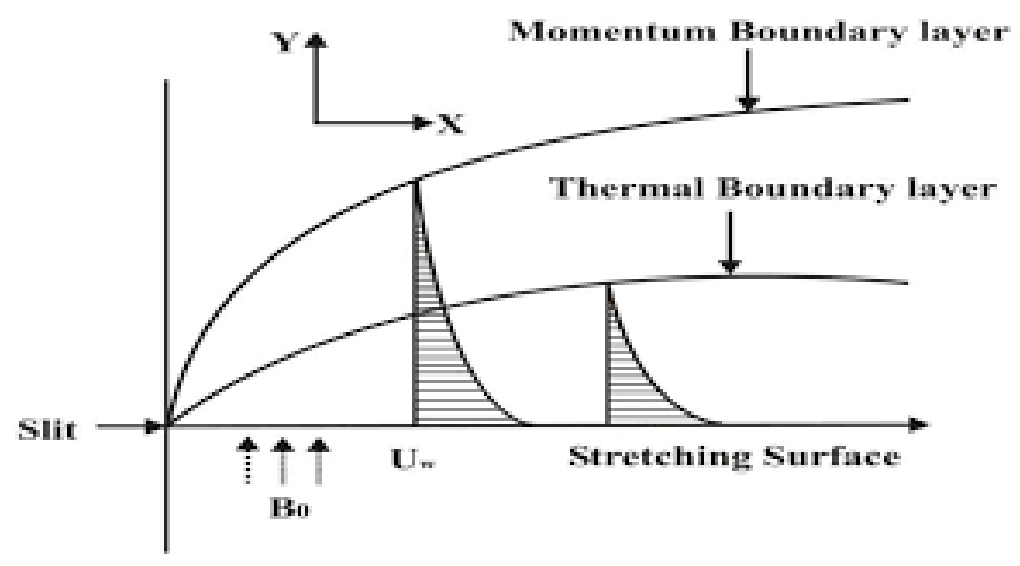

Fig.1. Two dimensional coordinate system and fluid flow mechanism of nanoparticle suspension.

The following are the basic nanofluid governing equations in their Cartesian form: Conservation of mass equation

$$
\frac{d u}{d x}+\frac{d v}{d y}=0
$$

Conservation of momentum equation (velocity)

$$
u \frac{d u}{d x}+v \frac{d u}{d y}=v \frac{d^{2} u}{d y^{2}}
$$

Conservation of thermal energy equation (temperature)

$$
u \frac{\partial T}{\partial x}+v \frac{\partial T}{\partial y}=\alpha_{m} \nabla^{2} T+\tau\left[D_{B} \frac{\partial C}{\partial y} \frac{\partial T}{\partial y}+\left(\frac{D_{T}}{T_{\infty}}\right)\left(\frac{\partial T}{\partial y}\right)^{2}\right]
$$

Conservation of nanoparticle equation (concentration)

$$
u \frac{\partial C}{\partial x}+v \frac{\partial C}{\partial y}=D_{B} \frac{\partial^{2} C}{\partial y^{2}}+\left(\frac{D_{T}}{T_{\infty}}\right) \frac{\partial^{2} T}{\partial y^{2}}-K_{0}\left(C-C_{\infty}\right)
$$

subjected to the boundary conditions

$$
\begin{aligned}
& y=0: u_{w}=a x^{n}, \quad v=0, \quad T=T_{w}, \quad C=C_{w}, \\
& y \rightarrow \infty: u=v=0, \quad T=T_{\infty}, \quad C=C_{\infty}
\end{aligned}
$$

where

$$
\alpha_{m}=\frac{K_{m}}{(\rho c)_{f}}, \quad \tau=\frac{(\rho c)_{p}}{(\rho c)_{f}}
$$


$\alpha_{m}$ denotes the thermal diffusivity, $\tau$ denotes the ratio between effective heat capacity of the nanoparticle material and heat capacity of the base fluid. In Eqs (2.1)-(2.4), $u, v$ denote velocity components along $x$ and $y$ axes respectively, $\rho_{f}$ is the density of the base fluid, $\vartheta$ is the kinematic viscosity, $a$ is a positive constant, $D_{B}$ is the Brownian diffusion coefficient, $D_{T}$ denotes the thermophoretic diffusion coefficient, $C$ is the volumetric volume expansion coefficient, $\rho_{p}$ is the density of the particles, $K_{0}$ denotes the chemical reaction parameter.

The similarity transformations to solve the governing equations are as follows

$$
\begin{aligned}
& \eta=y \sqrt{\frac{a(n+1)}{2 v}} x^{\frac{n-1}{2}}, \quad u=a x^{n} f^{\prime}(\eta), \\
& v=-\sqrt{\frac{a v(n+1)}{2}} x^{\frac{n-1}{2}}\left[f(\eta)+\left(\frac{n-1}{n+1}\right) \eta f^{\prime}(\eta)\right], \quad \theta(\eta)=\frac{T-T_{\infty}}{T_{w}-T_{\infty}}, \quad \phi(\eta)=\frac{C-C_{\infty}}{C_{w}-C_{\infty}} .
\end{aligned}
$$

Substituting the above similarity transformations represented by Eqs (2.8) in the governing Eqs (2.1)-(2.4) they reduce to

$$
\begin{aligned}
& f^{\prime \prime \prime}+f f^{\prime \prime}-\left[\frac{2 n}{n+1}\right] f^{\prime 2}=0, \\
& \frac{1}{\operatorname{Pr}} \theta^{\prime \prime}+f \theta^{\prime}+\operatorname{Nb} \theta^{\prime} \phi^{\prime}+\operatorname{Nt}\left(\theta^{\prime}\right)^{2}=0, \\
& \phi^{\prime \prime}+\operatorname{Le} f \phi^{\prime}+\frac{N t}{\mathrm{Nb}} \theta^{\prime \prime}-\gamma \operatorname{Le} \phi=0 .
\end{aligned}
$$

The transformed boundary conditions are

at

$$
\begin{aligned}
& \eta=0: f(0)=0, \quad f^{\prime}(0)=1, \quad \theta(0)=1, \quad \phi(0)=1, \\
& \text { at } \eta \rightarrow \infty: f^{\prime}(\infty)=0, \quad \theta(\infty)=0, \quad \phi(\infty)=0
\end{aligned}
$$

where prime ( )' denotes differentiation with respect to $\eta$. The physical parameters involved in the equations are defined as follows

$$
\begin{aligned}
& \operatorname{Pr}=\frac{v}{\alpha_{m}}, \quad \mathrm{Le}=\frac{v}{D_{B}}, \quad \mathrm{Nb}=\frac{(\rho c)_{p} D_{B}\left(C_{w}-C_{\infty}\right)}{(\rho c)_{f} v}, \quad N t=\frac{(\rho c)_{p} D_{T}\left(T_{w}-T_{\infty}\right)}{(\rho c)_{f} v T_{\infty}}, \\
& \gamma=K_{0} K_{x} \quad \text { where } \quad K_{x}=\frac{2}{a(n+1) x^{n-1}}
\end{aligned}
$$


Pr denotes the Prandtl number, Le is the Lewis number, $\mathrm{Nb}$ is the Brownian motion parameter, $N t$ is the thermophoresis parameter, $\gamma$ is the chemical reaction parameter.

Considering $n=1, N b=N t=0$ in Eqs (2.10) and (2.11) the boundary value problem reduces to the classical problem of flow, heat and mass transfer due to stretching surface in a viscous fluid, where the reduced equation has no physical significance for $\phi$.

Solving the equations for the local skin friction coefficient $C_{f x}$, Nusselt number $\mathrm{Nu}_{x}$, Sherwood number $\mathrm{Sh}_{x}$ which are defined as follows

$$
C_{f x}=-\frac{\tau_{w}}{\rho u_{w^{2}}} \quad \text { where } \quad \tau_{w}=\rho v\left[\frac{\partial u}{\partial y}\right] \quad \text { at } \quad y=0
$$

$\tau_{w}$ denotes the wall shear stress

$$
\begin{aligned}
& C_{f x}=\frac{-\rho v\left[\frac{\partial u}{\partial y}\right]}{\rho u_{w^{2}}} \quad \text { where } \quad u=a x^{n} f^{\prime}(\eta) \\
& {\left[\frac{\partial u}{\partial y}\right]=a x^{n} f^{\prime \prime}(\eta) \eta^{\prime} \quad \text { at } \quad y=0 \quad \text { where } \quad \eta^{\prime}=\frac{\partial \eta}{\partial y}=\sqrt{\frac{a(n+1)}{2 v}} x^{\frac{n-1}{2}}} \\
& C_{f x}=\frac{-v a x^{n} f^{\prime \prime}(\eta) \sqrt{\frac{a(n+1)}{2 v} x^{\frac{n-1}{2}}}}{a^{2} x^{2 n}}, \text { where } u_{w}=a x^{n} \\
& C_{f x}=-\frac{v}{a} x^{-n} x^{\frac{n-1}{2}} \sqrt{\frac{a}{v}} \sqrt{\frac{n+1}{2}} f^{\prime \prime}(\eta), \quad C_{f x}=-\sqrt{\frac{v}{a}} x^{-\frac{n+1}{2}} \sqrt{\frac{n+1}{2}} f^{\prime \prime}(\eta), \\
& C_{f x}=-\sqrt{\frac{v}{a}} \frac{1}{\sqrt{x^{n+1}}} \sqrt{\frac{n+1}{2}} f^{\prime \prime}(\eta), \quad \quad \sqrt{\frac{a x^{n+1}}{v}} C_{f x}=-\sqrt{\frac{n+1}{2}} f^{\prime \prime}(\eta), \\
& \operatorname{Re}_{x^{1 / 2}} C_{f x}=-\sqrt{\frac{n+1}{2}} f^{\prime \prime}(\eta) \\
& \mathrm{Nu}_{x}=\frac{x q_{w}}{k\left(T_{w}-T_{\infty}\right)} \text { where } k \text { is the thermal conductivity, } q_{w} \text { is heat flux } \\
& q_{w}=-k\left[\frac{\partial T}{\partial y}\right] \text { at } \quad y=0 \\
& \theta(\eta)=\frac{T-T_{\infty}}{T_{w}-T_{\infty}} \text { where } T=T_{\infty}+\theta(\eta)\left[T_{w}-T_{\infty}\right] \text { and } \frac{\partial T}{\partial y}=\left[T_{w}-T_{\infty}\right] \theta^{\prime}(\eta) \eta^{\prime} \text {, }
\end{aligned}
$$




$$
\begin{aligned}
& q_{w}=-k\left[T_{w}-T_{\infty}\right] \theta^{\prime}(\eta) \eta^{\prime}, \quad \mathrm{Nu}_{x}=\frac{-x k\left[T_{w}-T_{\infty}\right] \theta^{\prime}(\eta) \eta^{\prime}}{k\left[T_{w}-T_{\infty}\right]}, \\
& \mathrm{Nu}_{x}=-x \theta^{\prime}(\eta) \eta^{\prime} \quad \text { where } \quad \eta^{\prime}=\frac{\partial \eta}{\partial y}=\sqrt{\frac{a(n+1)}{2 v}} x^{\frac{n-1}{2}} \\
& \mathrm{Nu}_{x}=-x \theta^{\prime}(\eta) \sqrt{\frac{a(n+1)}{2 v}} x^{\frac{n-1}{2}} \\
& \mathrm{Nu}_{x}=-\theta^{\prime}(\eta) x^{\frac{n+1}{2}} \sqrt{\frac{a(n+1)}{2 v}}, \quad \mathrm{Nu}_{x}=-\theta^{\prime}(\eta) \sqrt{x^{n+1}} \sqrt{\frac{a}{v}} \sqrt{\frac{n+1}{2}}, \\
& \sqrt{\frac{v}{a x^{n+1}}} \mathrm{Nu}_{x}=-\sqrt{\frac{n+1}{2}} \theta^{\prime}(\eta), \quad \operatorname{Re}_{x^{-l / 2}} \mathrm{Nu}_{x}=-\sqrt{\frac{n+1}{2}} \theta^{\prime}(\eta), \\
& \mathrm{Sh}_{x}=\frac{x q_{m}}{D_{B}\left(C_{w}-C_{\infty}\right)}, \\
& \phi(\eta)=\frac{C-C_{\infty}}{C_{w}-C_{\infty}} \quad \text { where } \quad C=C_{\infty}+\phi(\eta)\left(C_{w}-C_{\infty}\right), \\
& q_{m}=-D_{B}\left[\frac{\partial C}{\partial y}\right] \quad \text { at } \quad y=0, \quad \frac{\partial C}{\partial y}=\left(C_{w}-C_{\infty}\right) \phi^{\prime}(\eta) \eta^{\prime}, \\
& \operatorname{Sh}_{x}=\frac{-x D_{B}\left(C_{w}-C_{\infty}\right) \phi^{\prime}(\eta) \eta^{\prime}}{D_{B}\left(C_{w}-C_{\infty}\right)}, \quad \operatorname{Sh}_{x}=-x \phi^{\prime}(\eta) \eta^{\prime}, \\
& \operatorname{Sh}_{x}=-x \phi^{\prime}(\eta) \sqrt{\frac{a(n+1)}{2 v}} x^{\frac{n-1}{2}}, \quad \operatorname{Sh}_{x}=-\phi^{\prime}(\eta) x^{\frac{n+1}{2}} \sqrt{\frac{a}{v}} \sqrt{\frac{n+1}{2}} \\
& \mathrm{Sh}_{x}=-\phi^{\prime}(\eta) \sqrt{x^{n+1}} \sqrt{\frac{a}{v}} \sqrt{\frac{n+1}{2}}, \quad \sqrt{\frac{v}{a x^{n+1}}} \mathrm{Sh}_{x}=-\sqrt{\frac{n+1}{2}} \phi^{\prime}(\eta) \text {, } \\
& \operatorname{Re}_{x^{-1 / 2}} \operatorname{Sh}_{x}=-\sqrt{\frac{n+1}{2}} \phi^{\prime}(\eta) \\
& \operatorname{Re}_{x^{1 / 2}} C_{f x}=-\sqrt{\frac{n+1}{2}} f^{\prime \prime}(\eta), \operatorname{Re}_{x}{ }_{-\frac{1}{2}} \mathrm{Nu}_{x}=-\sqrt{\frac{n+1}{2}} \theta^{\prime}(\eta), \operatorname{Re}_{x^{-1 / 2}} \operatorname{Sh}_{x}=-\sqrt{\frac{n+1}{2}} \phi^{\prime}(\eta) .
\end{aligned}
$$

Equations (2.9)-(2.11) are nonlinear partial differential equations which cannot be solved analytically.

\section{Method of solution}

To solve the nonlinear and coupled partial differential equations represented by Eqs (2.9)-(2.11), we apply the most effective technique in numerical analysis called 'Adam's Predictor Corrector Method' which 
helps solving distinctive problems relative to heat transfer, fluid mechanics, electrical systems, etc. The first step involves reducing the nonlinear differential equations of third order in $f$ and second order in $\theta$ and $\phi$ to a system of first order differential equations, so the problem is simplified.

$$
\begin{aligned}
& f^{\prime \prime \prime}=-f f^{\prime \prime}+\frac{2 n}{n+1} f^{\prime 2}, \\
& \theta^{\prime \prime}=-\operatorname{Pr}\left[f \theta^{\prime}+\operatorname{Nb} \theta^{\prime} \phi^{\prime}+N t\left(\theta^{\prime}\right)^{2}\right], \\
& \phi^{\prime \prime}=-\operatorname{Le} f \phi^{\prime}-\frac{N t}{\mathrm{Nb}} \theta^{\prime \prime}+\gamma \operatorname{Le} \phi .
\end{aligned}
$$

The above equations are solved independently using FORTRAN programming by converting each of them using different variables of first order as follows:

Equation (3.1) is represented as below and defines the system of equations for $f$

$$
\begin{aligned}
& f=y_{1}, \quad f^{\prime}=y_{2}, \quad f^{\prime \prime}=y_{3}, \\
& y_{1}^{\prime}=y_{2}, \quad y_{2}^{\prime}=y_{3}, \quad y_{3}^{\prime}=-y_{1} y_{3}+\frac{2 n}{n+1} y_{2}{ }^{2} .
\end{aligned}
$$

Boundary conditions with respect to $\eta$ for $f$ are

at

$$
\eta=0: y_{1}(0)=0, \quad y_{2}(0)=1
$$

at

$$
\eta \rightarrow \infty: y_{2}(\infty)=0 \text {. }
$$

We assume initial guess value as $\alpha$ for $y_{3}$ ie $y_{3}(0)=\alpha$. Hence $y_{1}(0)=0, y_{2}(0)=1, y_{3}(0)=\alpha$ where $\alpha$ needs to be found out using Newton's method to satisfy $y_{2}\left(\eta_{\infty}\right)=0$.

Equations (3.2) and (3.3) are represented as below and define the system of equations for $\theta$ and $\phi$

$$
\begin{aligned}
& y_{1}=\theta, \quad y_{2}=\theta^{\prime}, \quad y_{2}^{\prime}=-\operatorname{Pr}\left[f y_{2}+\mathrm{Nb} y_{2} y_{4}+N t y_{2}{ }^{2}\right], \\
& y_{3}=\phi, \quad y_{4}=\phi^{\prime}, \quad y_{4}^{\prime}=-\operatorname{Le} f y_{4}-\frac{N t}{N b} y_{2}{ }^{\prime}+\gamma \operatorname{Le} y_{3} .
\end{aligned}
$$

The boundary conditions with respect to $\eta$ for $\theta$ and $\phi$ are as follows

at

$$
\begin{aligned}
& \eta=0: y_{1}(0)=1, \quad y_{3}(0)=1, \\
& \eta \rightarrow \infty: y_{1}(0)=0, \quad y_{3}(0)=0
\end{aligned}
$$

$\alpha, \beta$ values which are the unknowns with respect to $\theta$ and $\phi$ are found out starting with initial guess and correcting the values using Newton's method to satisfy the end conditions as follows 


$$
\left(\begin{array}{l}
\alpha \\
\beta
\end{array}\right)^{\text {New }}=\left(\begin{array}{l}
\alpha \\
\beta
\end{array}\right)^{\text {Old }}-\left[\begin{array}{ll}
\frac{\partial y_{1}}{\partial \alpha} & \frac{\partial y_{1}}{\partial \beta} \\
\frac{\partial y_{3}}{\partial \alpha} & \frac{\partial y_{3}}{\partial \beta}
\end{array}\right]_{\eta=\infty}^{-1}\left(\begin{array}{l}
y_{2, N 4} \\
y_{4, N 4}
\end{array}\right)
$$

The boundary value problem is converted to an initial value problem by reducing the equations as shown above and the initial value problem is solved using Adam's predictor corrector method by assigning an approximate initial value with step size $h=0.005$ (1200 elements) and $\eta$ at its max to be 6 . The solution is obtained for different parameters used and convergence is achieved with a change in a single parameter. The criteria for convergence are the approximation up to three significant digits. The results derived through computation are illustrated in graphs for a clear picture of the numerical problem. The tables below show the variation of dimensionless heat and mass transfer rates against $N t$ and $\mathrm{Nb}$ for different values of chemical reaction parameter $\gamma$.

Table1. Computation of the heat transfer rate $-\theta^{\prime}(0)$, mass transfer rate $-\phi^{\prime}(0)$ against the thermophoretic parameter $N t$ when $N b=0.5$ for different values of the chemical reaction parameter $\gamma$.

\begin{tabular}{|l|c|c|c|c|c|c|}
\hline$N \boldsymbol{N}$ & \multicolumn{2}{|c|}{$\gamma=0.5$} & \multicolumn{2}{c|}{$\gamma=1.0$} & \multicolumn{2}{c|}{$\gamma=1.5$} \\
\hline & $-\theta^{\prime}(0)$ & $-\phi^{\prime}(0)$ & $-\theta^{\prime}(0)$ & $-\phi^{\prime}(0)$ & $-\theta^{\prime}(0)$ & $-\phi^{\prime}(0)$ \\
\hline 0.1 & 0.542 & 1.649 & 0.515 & 2.078 & 0.497 & 2.428 \\
\hline 0.14 & 0.525 & 1.649 & 0.498 & 2.086 & 0.48 & 2.44 \\
\hline 0.18 & 0.509 & 1.651 & 0.481 & 2.095 & 0.464 & 2.453 \\
\hline 0.22 & 0.493 & 1.655 & 0.465 & 2.105 & 0.448 & 2.467 \\
\hline 0.26 & 0.478 & 1.659 & 0.45 & 2.117 & 0.433 & 2.481 \\
\hline 0.3 & 0.464 & 1.665 & 0.435 & 2.129 & 0.418 & 2.496 \\
\hline 0.34 & 0.45 & 1.672 & 0.421 & 2.141 & 0.404 & 2.511 \\
\hline 0.38 & 0.436 & 1.679 & 0.408 & 2.155 & 0.391 & 2.527 \\
\hline 0.42 & 0.423 & 1.688 & 0.395 & 2.169 & 0.378 & 2.543 \\
\hline 0.46 & 0.41 & 1.697 & 0.382 & 2.183 & 0.366 & 2.56 \\
\hline 0.5 & 0.398 & 1.707 & 0.37 & 2.198 & 0.354 & 2.576 \\
\hline
\end{tabular}

Table2. Computation of the heat transfer rate $-\theta^{\prime}(0)$, mass transfer rate $-\phi^{\prime}(0)$ against the Brownian motion Parameter $\mathrm{Nb}$ when $N t=0.5$ for different values of the chemical reaction parameter $\gamma$.

\begin{tabular}{|c|c|c|c|c|c|c|}
\hline $\boldsymbol{N b}$ & \multicolumn{2}{|c|}{$\gamma=0.5$} & \multicolumn{2}{c|}{$\gamma=1.0$} & \multicolumn{2}{c|}{$\gamma=1.5$} \\
\hline & $-\theta^{\prime}(0)$ & $-\phi^{\prime}(0)$ & $-\theta^{\prime}(0)$ & $-\phi^{\prime}(0)$ & $-\theta^{\prime}(0)$ & $-\phi^{\prime}(0)$ \\
\hline 0.1 & 0.671 & 0.936 & 0.647 & 1.818 & 0.633 & 2.4 \\
\hline 0.14 & 0.638 & 1.229 & 0.613 & 1.973 & 0.599 & 2.483 \\
\hline 0.18 & 0.607 & 1.388 & 0.581 & 2.055 & 0.566 & 2.525 \\
\hline 0.22 & 0.577 & 1.487 & 0.55 & 2.105 & 0.534 & 2.549 \\
\hline 0.26 & 0.548 & 1.553 & 0.52 & 2.136 & 0.505 & 2.563 \\
\hline 0.3 & 0.52 & 1.6 & 0.492 & 2.158 & 0.476 & 2.571 \\
\hline 0.34 & 0.493 & 1.635 & 0.465 & 2.173 & 0.449 & 2.576 \\
\hline 0.38 & 0.468 & 1.66 & 0.44 & 2.183 & 0.424 & 2.578 \\
\hline 0.42 & 0.444 & 1.68 & 0.416 & 2.19 & 0.399 & 2.578 \\
\hline 0.46 & 0.421 & 1.695 & 0.392 & 2.195 & 0.376 & 2.578 \\
\hline 0.5 & 0.398 & 1.707 & 0.37 & 2.198 & 0.354 & 2.576 \\
\hline
\end{tabular}




\section{Results and discussions}

To provide a physical insight to the flow problem, numerical computations involving various parameters and their influence on the dimensionless velocity, temperature and nanoparticle concentration of the fluid flow are presented graphically below.

\subsection{Profiles of $\boldsymbol{f}(\boldsymbol{\eta}), \theta(\boldsymbol{\eta}), \phi(\boldsymbol{\eta})$}

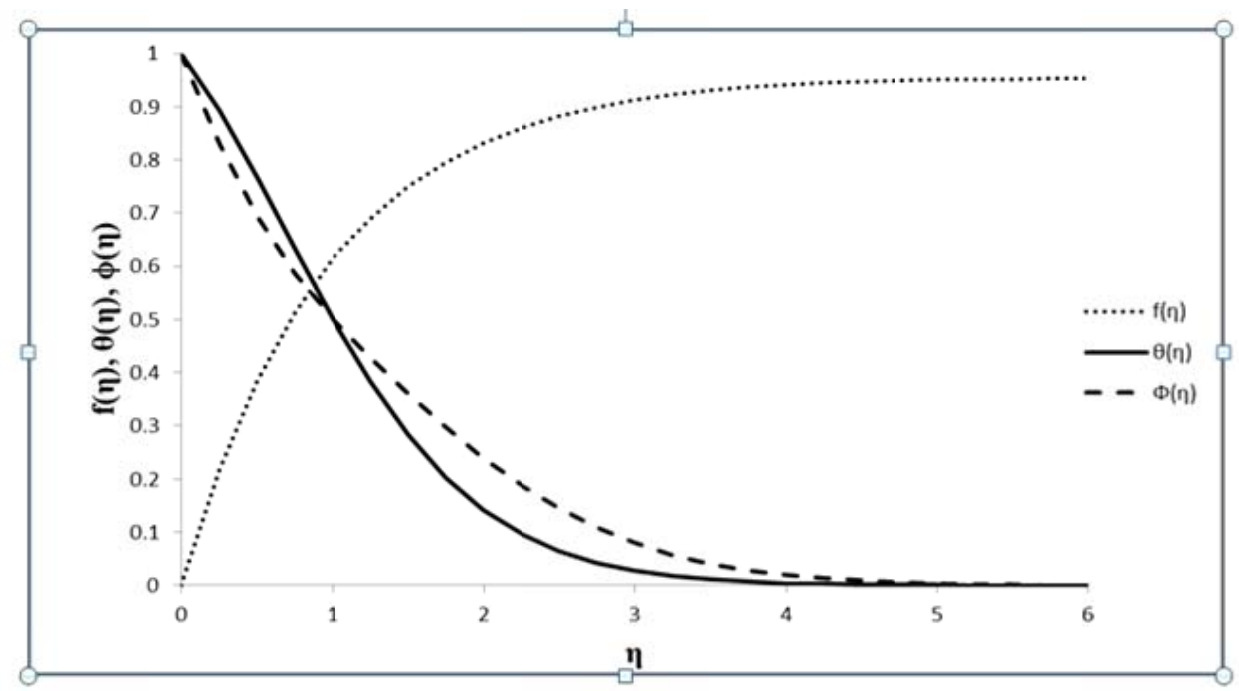

Fig.1. Profiles of the stream function, temperature function and nanoparticle concentration function for $N t=0.5, \mathrm{Nb}=0.5, \operatorname{Pr}=2.0, \mathrm{Le}=2.0, \eta=6, n=2$.

The above graph satisfies the transformed boundary conditions of stream, temperature and nanoparticle concentration functions varying from 0 to $l$ for $f$ and $l$ to $\theta$ for $\theta$ and $\phi$.

\subsection{Influence of $\mathbf{N b}$ on $\theta(\eta)$}

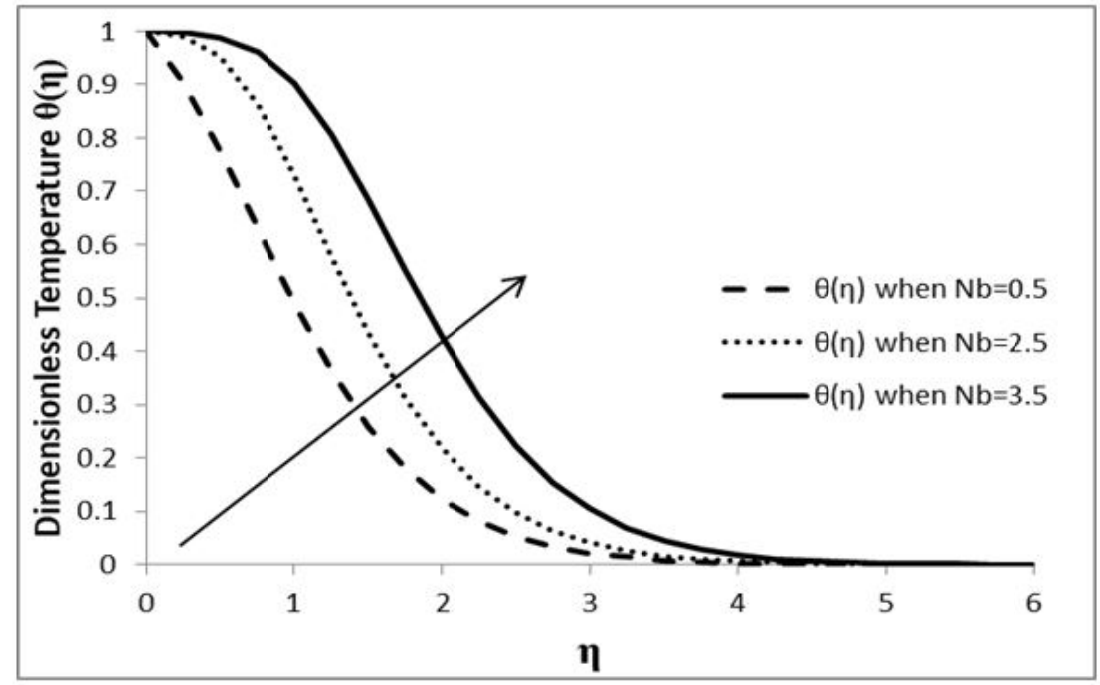

Fig.2. Effect of the Brownian motion parameter $N b$ on temperature distribution for $N t=0.5, \operatorname{Pr}=2.0$, $\mathrm{Le}=2.0, \eta=6, n=2, \gamma=0.0$ 


\subsection{Influence of $\mathrm{Nb}$ on $\phi(\eta)$}

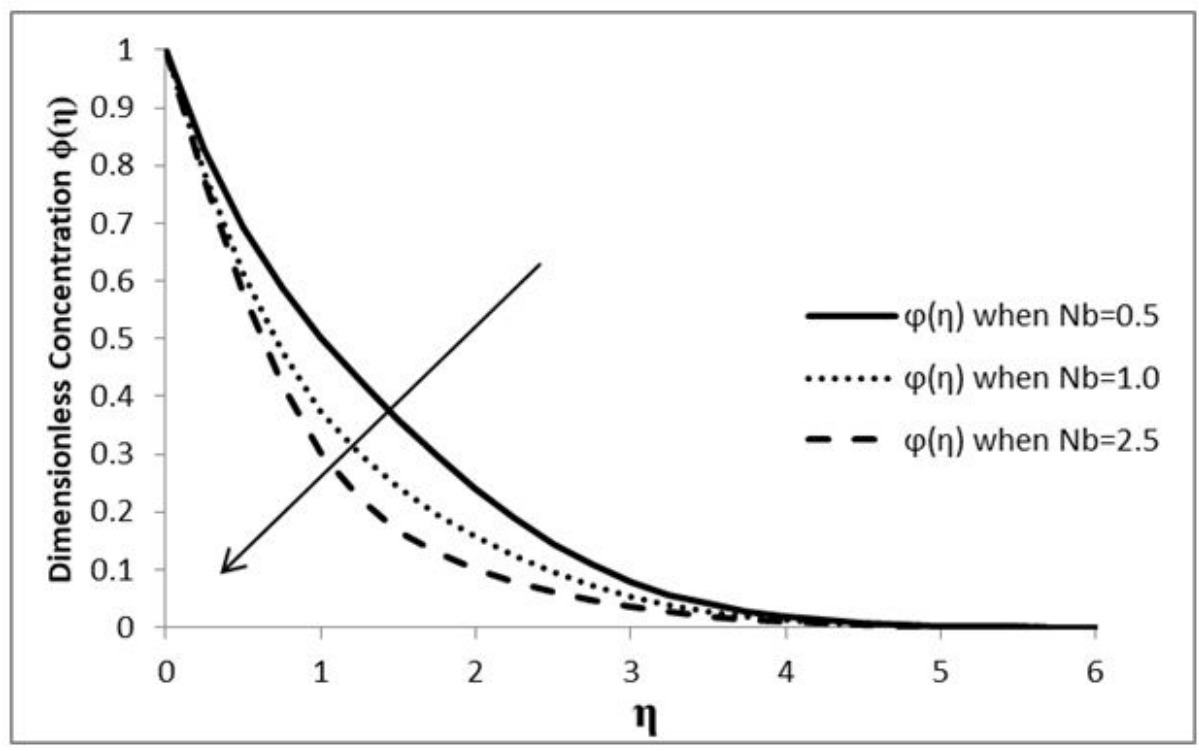

Fig.3. Effect of the Brownian motion parameter $\mathrm{Nb}$ on concentration distribution for $N t=0.5, \operatorname{Pr}=2.0, \mathrm{Le}=2.0, \eta=6, n=2, \gamma=0.0$.

The Brownian motion parameter has a strong influence on the dimensionless temperature and nanoparticle concentration (volume fraction) of the fluid. The concentration of the fluid decreases with an increase in $\mathrm{Nb}$ as shown in Fig.3 since the Brownian motion warms the boundary layer making the particles move away from the fluid regime. On the other hand, with an increase in $\mathrm{Nb}$ the thermal conduction increases due to the motion of nanoparticles and this gets stronger with smaller particles.

4.4. Influence of $\gamma$ on $\theta(\eta)$

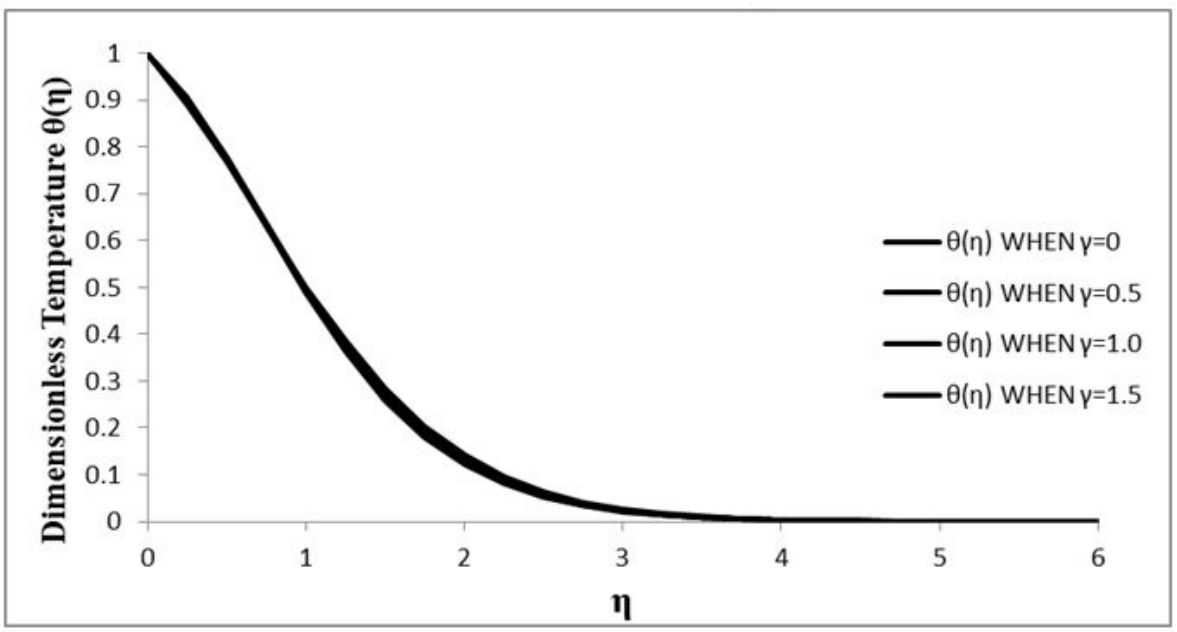

Fig.4. Effect of the chemical reaction parameter $\gamma$ on temperature distribution when $\mathrm{Nb}=N t=0.5$, $\operatorname{Pr}=2.0, \mathrm{Le}=2.0, \eta=6, n=2$. 
4.5. Influence of $\boldsymbol{\gamma}$ on $\phi(\eta)$

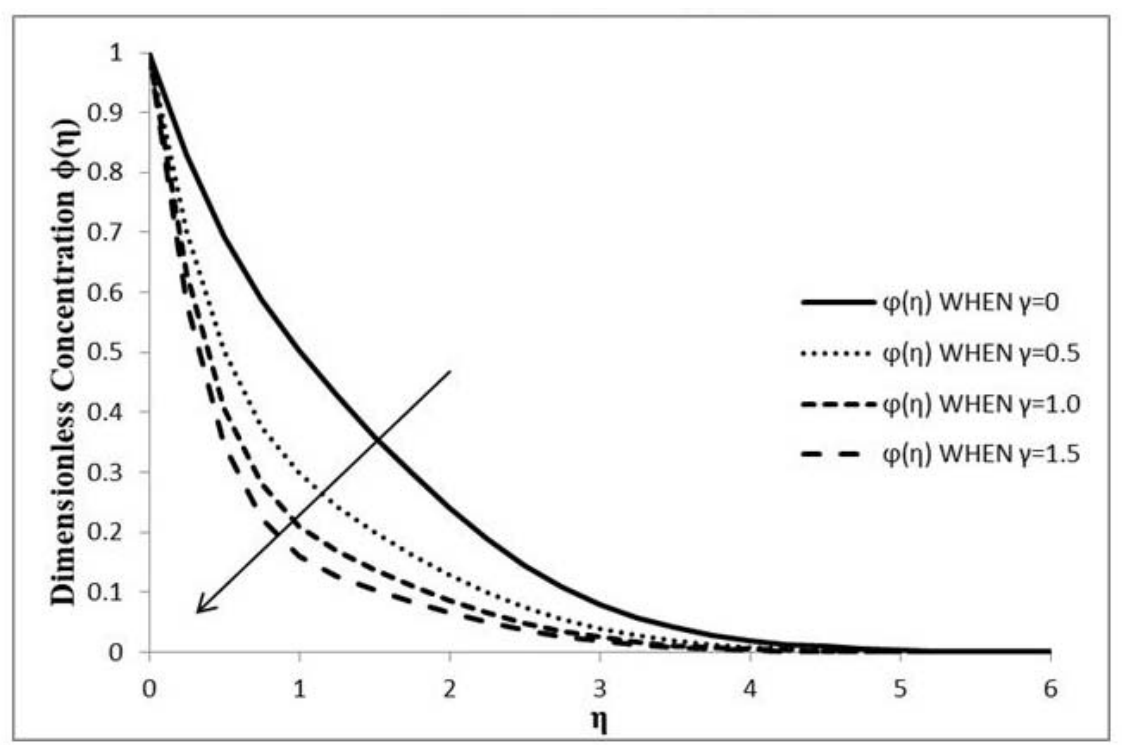

Fig.5. Effect of the chemical reaction parameter $\gamma$ on concentration distribution when $N b=N t=0.5$, $\operatorname{Pr}=2.0, \mathrm{Le}=2.0, \eta=6, n=2$.

Chemical reaction added has no effect on the temperature of the fluid as seen in Fig.4, but with an increase in the value of $\gamma$ the dimensionless concentration decreases making the particles move away from the surface as seen in Fig.5. Chemical reaction results in chemical dissipation thus reduce the concentration profile.

\subsection{Influence of $N t$ on $\theta(\eta)$}

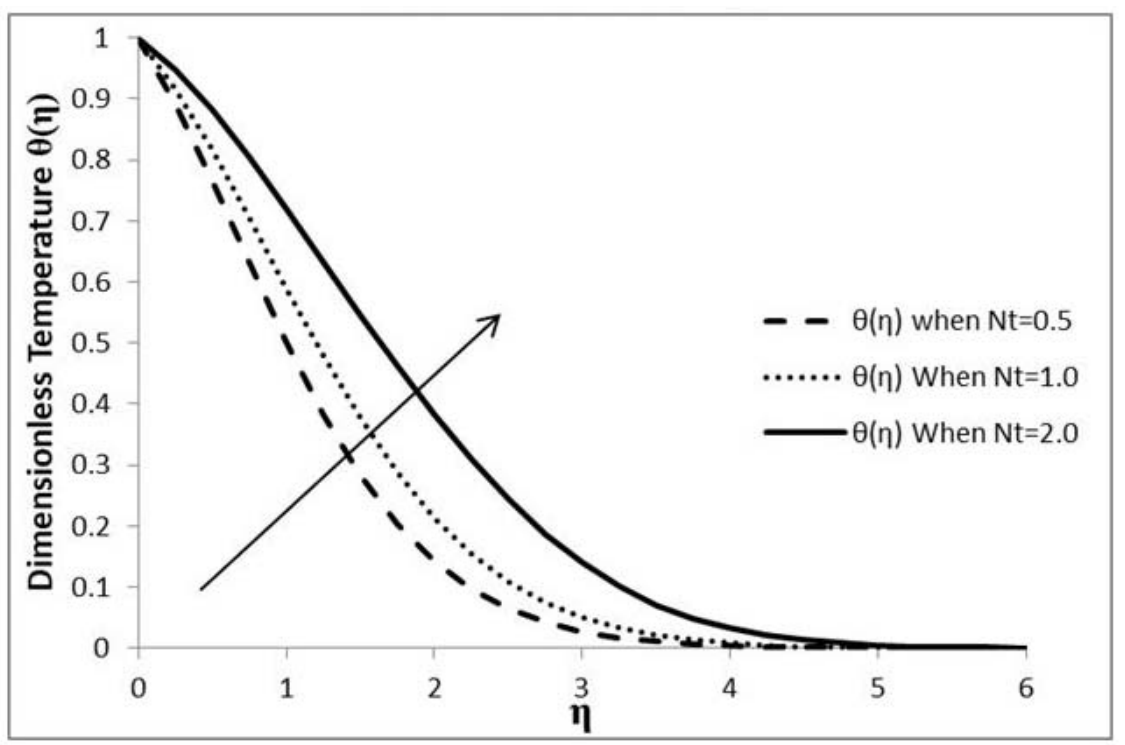

Fig.6. Effect of the thermophoresis parameter $N t$ on temperature distribution for $N b=0.5, \operatorname{Pr}=2.0$, $\mathrm{Le}=2.0, \eta=6, n=2$ 
4.7. Influence of $N t$ on $\phi(\eta)$

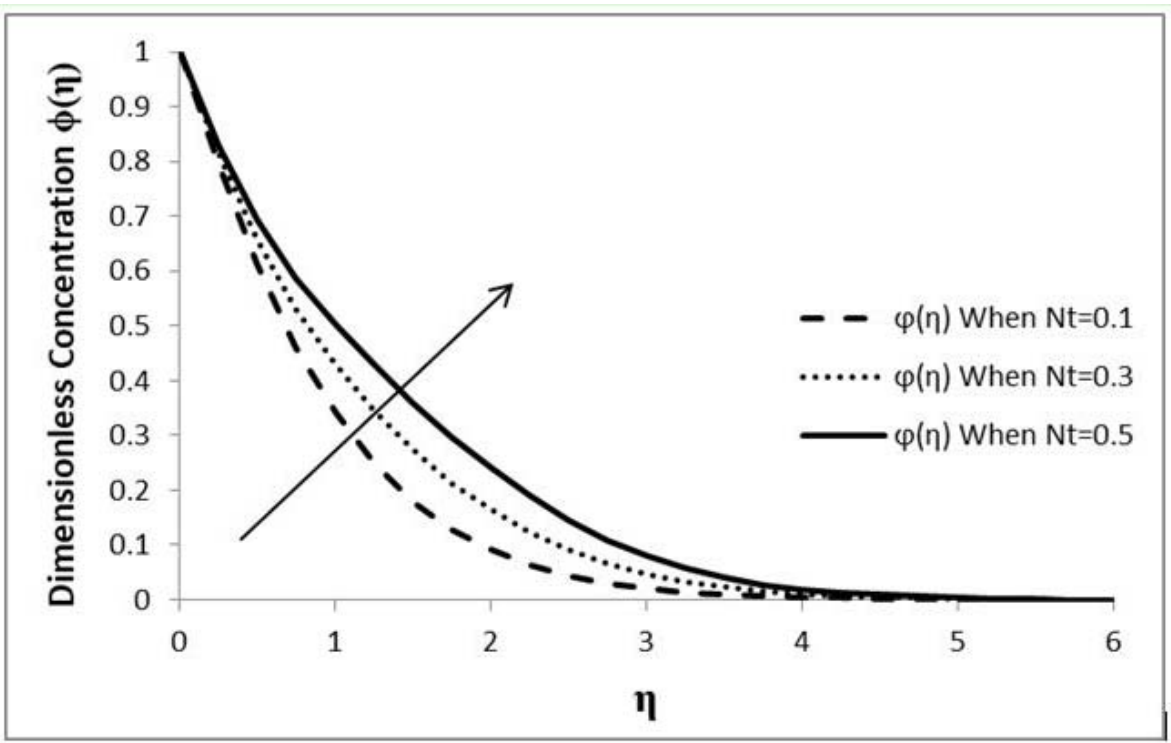

Fig.7. Effect of the thermophoresis parameter $N t$ on concentration distribution for $N b=0.5, \operatorname{Pr}=2.0$,

$\mathrm{Le}=2.0, \eta=6, n=2$.

With an increase in the thermophoresis parameter, the fluid temperature and nanoparticle concentration increase as observed in Fig.6, Fig.7. This is due to the fact that thermophoresis warms the boundary layer for lesser values of $\mathrm{Pr}$, Le resulting in decreasing the rate of heat and mass transfer of the fluid.

\subsection{Influence of $\boldsymbol{n}$ on $f^{\prime}(\eta)$}

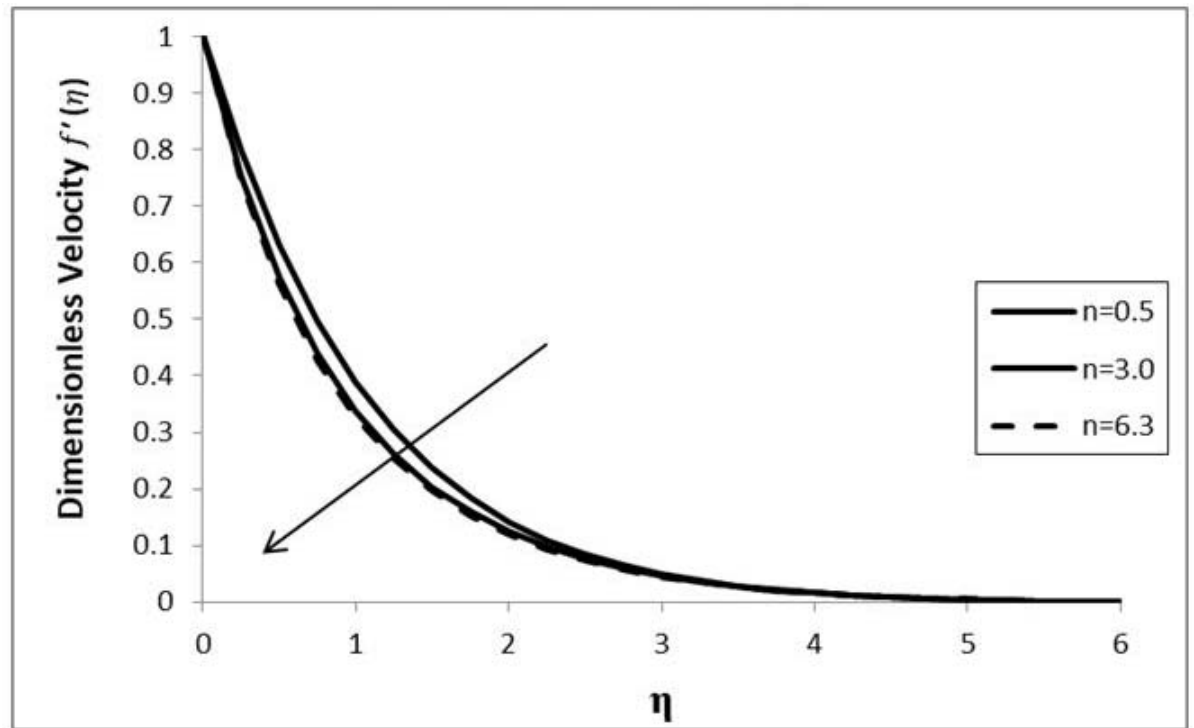

Fig.8. Effect of the stretching parameter $n$ on velocity distribution for $N b=0.5, N t=0.5$, $\operatorname{Pr}=2.0, \mathrm{Le}=2.0, \eta=6$. 
4.9. Influence of $n$ on $\theta(\eta)$

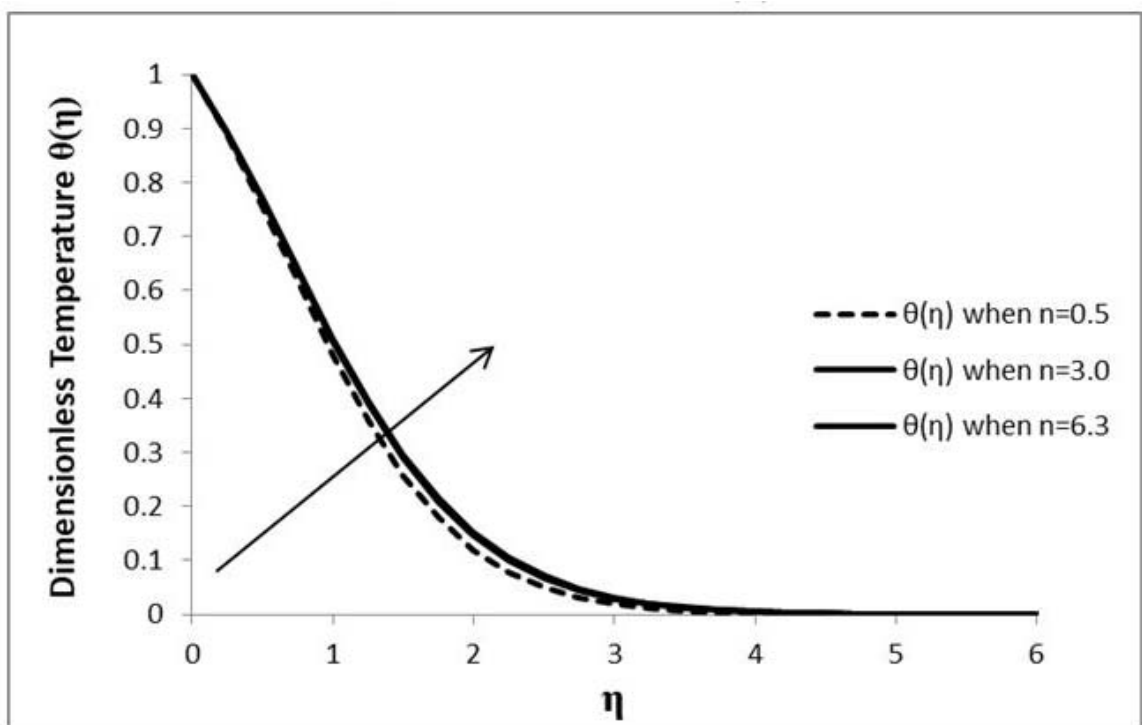

Fig.9. Effect of the stretching parameter $n$ on temperature distribution for $N b=0.5, N t=0.5$, $\operatorname{Pr}=2.0, \mathrm{Le}=10, \eta=6$

\subsection{Influence of $\boldsymbol{n}$ on $\phi(\eta)$}

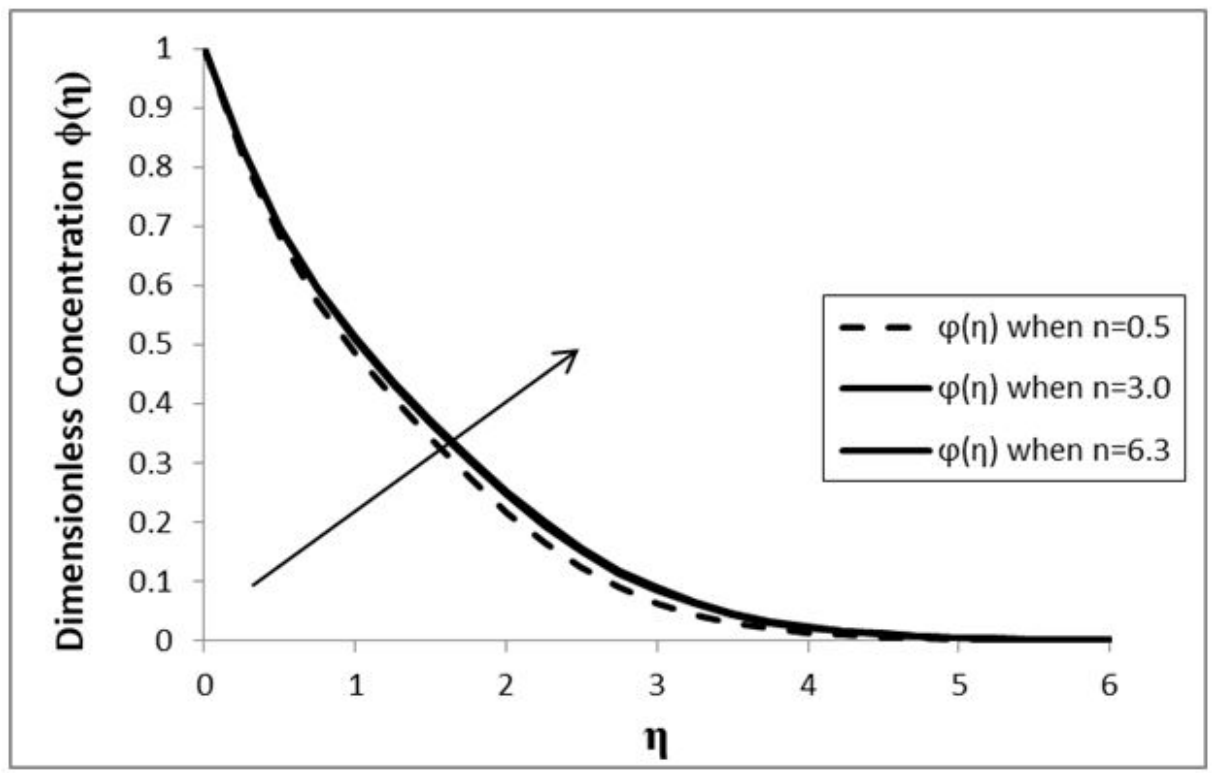

Fig.10. Effect of the stretching parameter $n$ on concentration distribution for $N b=0.5, N t=0.5$, $\operatorname{Pr}=2.0, \mathrm{Le}=10, \eta=6$

With an increase in the nonlinear stretching parameter, the velocity profile decreases, whereas the temperature and concentration profiles at the boundary layer of the fluid increase with a decrease in the heat and mass transfer rates as shown in Figs 8, 9, 10 respectively. 


\subsection{Influence of Le on $\theta(\eta)$}

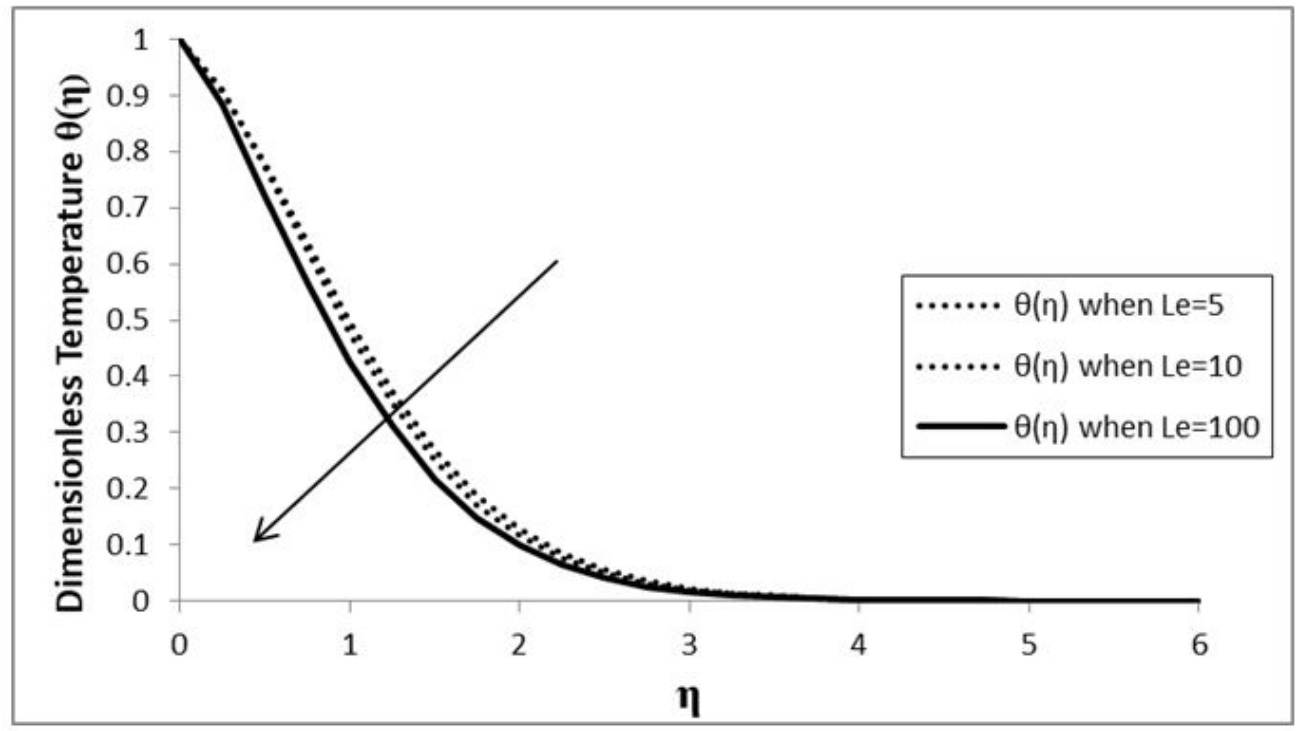

Fig.11. Effect of the Lewis number Le on temperature distribution for $\mathrm{Nb}=N t=0.5, \operatorname{Pr}=2.0, n=2, \eta=6$.

\subsection{Influence of Le on $\phi(\eta)$}

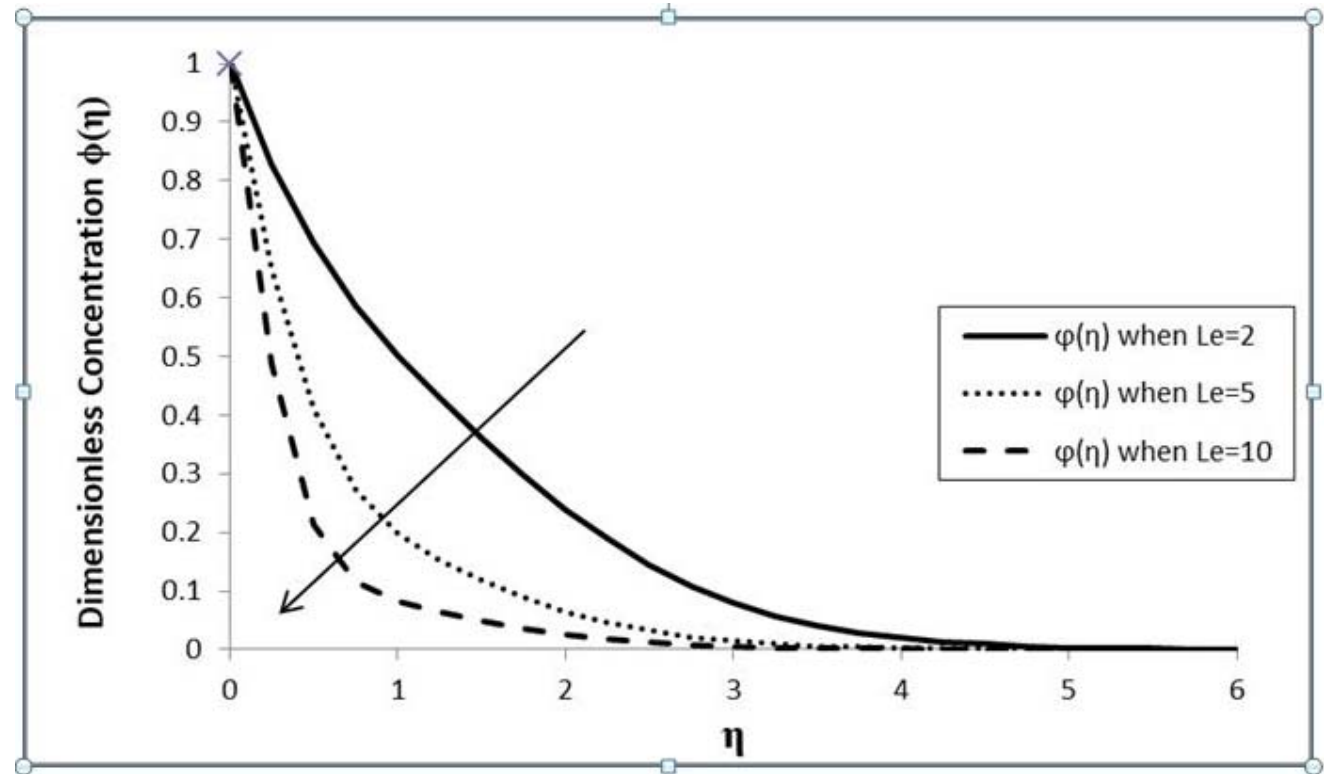

Fig.12. Effect of the Lewis number Le on concentration distribution for $\mathrm{Nb}=N t=0.5, \operatorname{Pr}=2.0, n=2, \eta=6$.

The Lewis number is defined as the ratio of thermal diffusivity to mass diffusivity. As seen in Figs 11, 12 both the temperature and concentration profiles of the fluid decrease with an increase in the Lewis number. But the decrease in concentration is seen clearly with a small difference in the Lewis number, whereas the case is reversed in the temperature profile. As Le reaches 100, a small difference is seen in the temperature profile. This 
is due to the fact that the thickness of the boundary layer concentration function is smaller compared to the thermal boundary layer thickness. The Lewis number reduces the thickness of $\theta(\eta)$ and $\phi(\eta)$.

\subsection{Influence of $\gamma$ on $\theta^{\prime}(\theta)$ against $N t$}

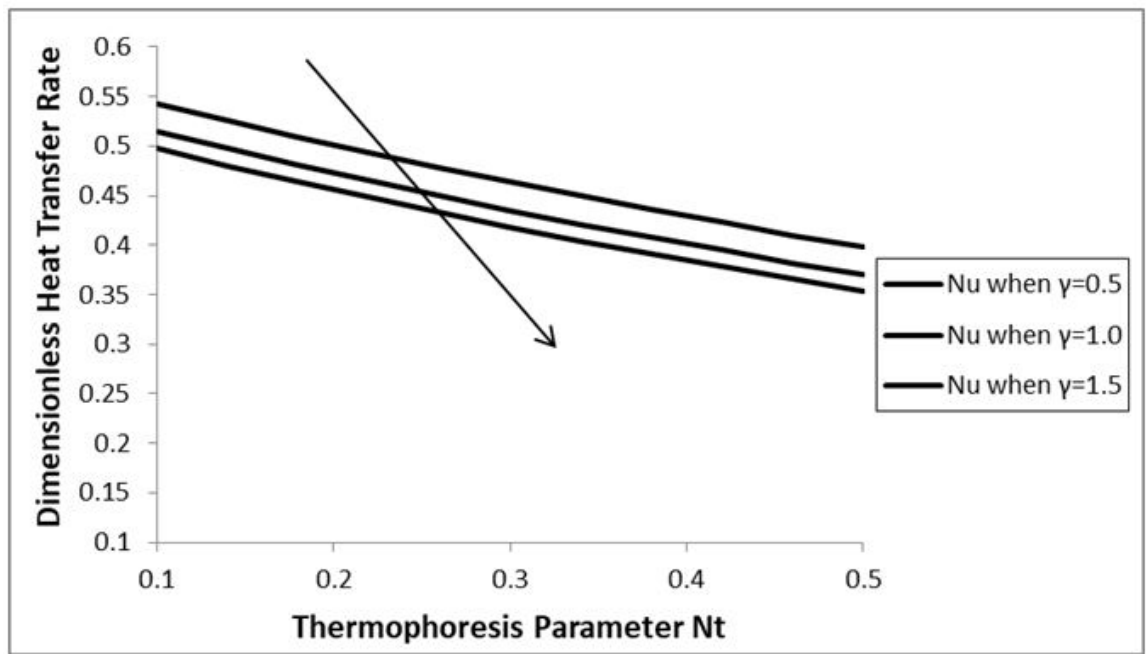

Fig.13. Variation of the dimensionless heat transfer rate with the thermophoresis parameter $N t$ when $\mathrm{Nb}=0.5$.

\subsection{Influence of $\boldsymbol{\gamma}$ on $\phi^{\prime}(0)$ against $N \boldsymbol{t}$}

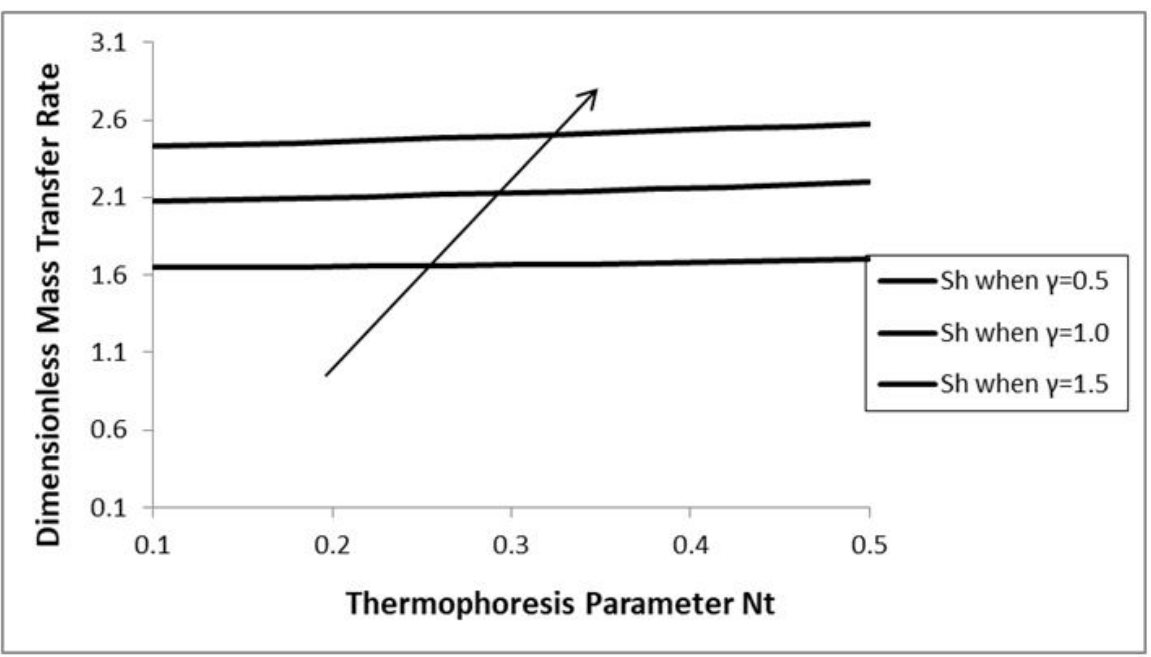

Fig.14. Variation of the dimensionless mass transfer rate with the thermophoresis parameter $N t$ when $\mathrm{Nb}=0.5$.

The variation of heat and mass transfer rates against the thermophoresis parameter for distinct values of chemical reaction are presented in Figs 13, 14. $\theta(\eta)$ decreases whereas $\phi(\eta)$ increases with an increase in $\gamma$ due to the reduced boundary layer thickness. 
4.15. Influence of $\boldsymbol{\gamma}$ on $\theta^{\prime}(0)$ against $N b$

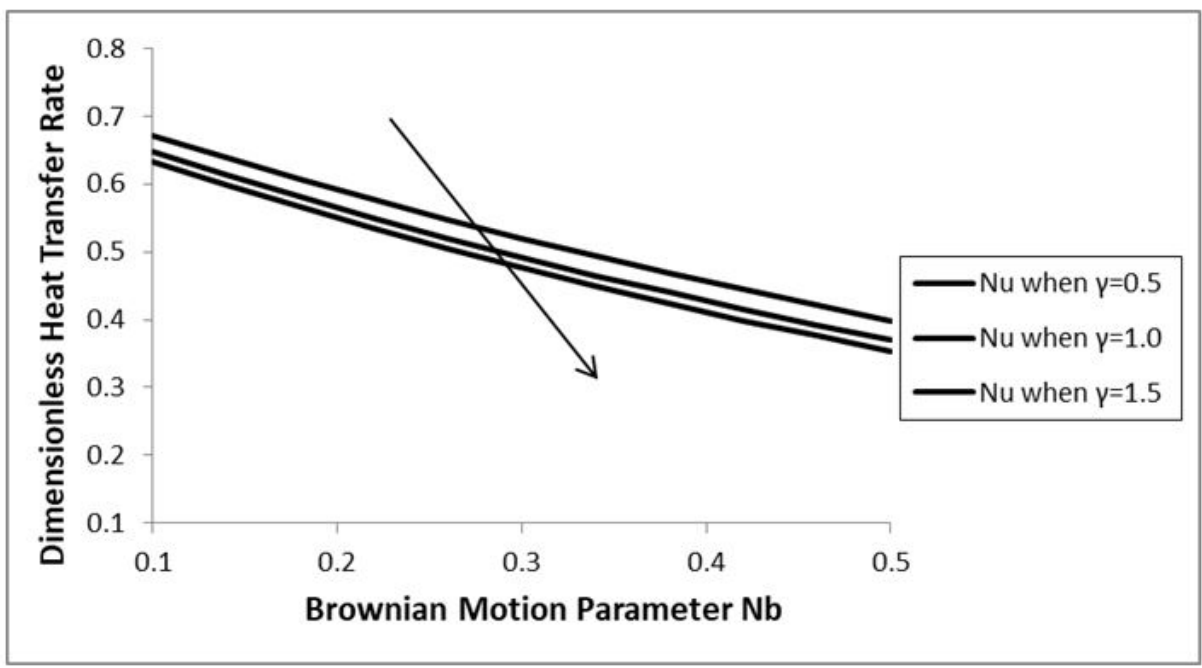

Fig.15. Variation of the dimensionless heat transfer rate with the Brownian motion parameter $\mathrm{Nb}$ when $N t=0.5$.

4.16. Influence of $\boldsymbol{\gamma}$ on $\phi^{\prime}(0)$ against $\boldsymbol{N b}$

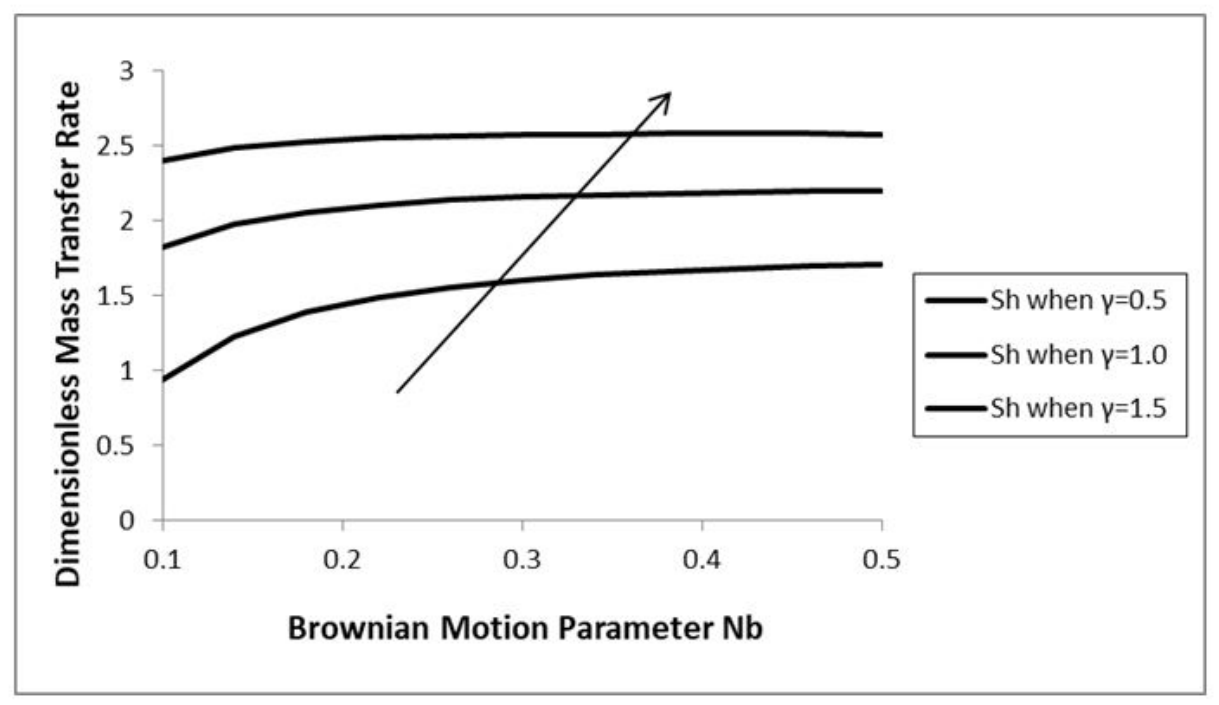

Fig.16. Variation of the dimensionless mass transfer rate with the Brownian motion parameter $\mathrm{Nb}$ when $N t=0.5$.

The influence of chemical reaction on the heat and mass transfer rate of the fluid flow against the Brownian motion parameter is shown in graphs 15,16 . The Nusselt number reduces, whereas the Sherwood number increases due to the change in the thickness of the thermal and concentration layers of the fluid in comparison to the velocity boundary layer. 


\section{Conclusions}

The following conclusions are drawn:

1. An increase in the Brownian motion parameter $\mathrm{Nb}$ increases the dimensionless temperature $\theta(\eta)$ and reduces the dimensionless concentration $\phi(\eta)$.

2. An increase in the chemical reaction parameter $\gamma$ has no influence on the temperature but the concentration drastically reduces due to the movement of nanoparticles of the fluid.

3. An increase in the thermophoresis parameter $N t$ increases the temperature distribution and concentration distribution of the fluid.

4. An increase in the stretching parameter reduces the velocity and increases the temperature and concentration distribution profile.

5. An increase in the Lewis number reduces the temperature and concentration of the fluid. But a major change in the concentration distribution is noticed due to the thickness of the boundary layer concentration in comparison to the thermal boundary layer thickness.

6. Variations of dimensionless heat and mass transfer rates against the thermophoresis parameter, Brownian motion parameter for different values of the chemical reaction parameter $\gamma$ have been studied and analyzed.

\section{Nomenclature}

$$
\begin{aligned}
a & - \text { constant } \\
C & - \text { nano particle volume fraction } \\
C_{w} & - \text { nano particle volume fraction } \\
C_{\infty} & - \text { ambientnano particle volume fraction } \\
\mathrm{Nb} & - \text { Brownian motion parameter } \\
N t & - \text { thermophoresis parameter } \\
n & - \text { stretching parameter } \\
\mathrm{Pr} & - \text { Prandtl number } \\
T & - \text { temperature on the plate } \\
T_{w} & - \text { temperature at the plate } \\
T_{\infty} & - \text { ambient temperature attained } \\
(x, y) & - \text { Cartesian coordinates } \\
\alpha_{m} & - \text { thermal diffusivity } \\
\beta & - \text { volumetric expansion coefficient of fluid } \\
\theta(\eta) & - \text { dimensionless temperature } \\
\gamma & - \text { chemical reaction parameter } \\
\eta & - \text { similarity } V \\
\psi & - \text { stream function } \\
v & - \text { kinematic viscosity of the fluid } \\
\rho c_{p} & - \text { effective heat capacity of nano particle } \\
\rho c_{f} & - \text { heat capacity of the fluid } \\
\rho_{f} & - \text { fluid density } \\
\rho_{p} & - \text { nano particle mass density } \\
\tau & - \text { torsion parameter defined by } \frac{\rho c_{p}}{\rho c_{f}} \\
\phi(\eta) & - \text { rescaled nano particle volume fraction }
\end{aligned}
$$




\section{Subscripts}

$\mathrm{D}_{\mathrm{B}}-$ Brownian diffusion coefficient

$D_{T} \quad$ - thermophoretic diffusion coefficient

$f_{\eta}$ - dimensionless stream function

Le - Lewis number

$\mathrm{Nu}_{x}$ - Nusselt number

$\mathrm{Sh}_{x}$ - Sherwood number

$u, v$ - velocity components along $x, y$ axes

$u_{w}$ - velocity of stretching sheet

$q_{m} \quad$ - wall mass flux

$q_{w}-$ wall heat flux

$w$ - condition on the sheet

$\infty-$ condition far away from the plate

\section{References}

[1] Sakiadis B.C. (1961): Boundary layer behaviour on continuous solid surfaces: I. Boundary layer equations for two dimensional and axisymmetric flow, II. The boundary layer on a continuous flat surface.https://doi.org/10.1002/aic.690070108, https://doi.org/10.1002/aic.690070211.

[2] Crane L.J. (1970): Flow past a stretching plate. - Journal of Applied Mathematics and Physics (ZAMP), vol.21, pp.645-647 http://dx.doi.org/10.1007/BF01587695.

[3] Anderson JD. (2009): Explicit finite difference methods: some selected applications to inviscid and viscous flows.In: Comput Fluid Dyn. Berlin Heidelberg: Springer-Verlag.

[4] Hayat T. and Waqas M. (2014): Effects of Joule heating and thermophoresis on stretched flow with convective boundary conditions.- Scientia Iranica. Transaction B, Mechanical Engineering, vol.21, pp.682-692.

[5] Rana P. and Bhargava R. (2011): Flow and heat transfer of a nanofluid over a nonlinearly stretching sheet: A numerical study.- https://doi.org/10.1016/j.cnsns.2011.05.009.

[6] Sheikholeslami M. (2016):CVFEM for magnetic nanofluid convective heat transfer in a porous curved enclosure. The European Physical Journal Plus, vol.131, 253.

[7] Hayat T., Waqas M., Shehzad S.A. and Alsaedi A. (2016):On model of Burgers fluid subject to magneto nanoparticles and convective conditions. - Journal of Molecular Liquids, vol.222,pp.181-187.

[8] WaqasM., Muhammad Farooq Muhammad Ijaz Khan Ahmed Alsaedi, Hayat T. and Yasmeen T. (2016): Magnetohydrodynamic (MHD) mixed convection flow of micropolar liquid due to nonlinear stretched sheet with convective condition. - International Journal of Heat and Mass Transfer, vol.102, pp.766-772.

[9] Hayat T., Waqas M., Shehzad S.A. and Alsaedi A. (2016): Chemically reactive flow of third grade fluid by an exponentially convected stretching sheet. - Journal of Molecular Liquids, vol.223, pp.853-860.

[10] Hayat T., Waqas M., Shehzad S.A. and Alsaedi A. and Alsaedi A. (2016): On 2D stratified flow of an Oldroyd-B fluid with chemical reaction: An application of non-Fourier heat flux theory.- Journal of Molecular Liquids, vol.223, pp.566-571.

[11] Hayat T., QayyumS., Waqas M. and Alsaedi A. (2016): Thermally radiative stagnation point flow of Maxwell nanofluid due to unsteady convectively heated stretched surface. - Journal of Molecular Liquids, vol.224,pp.801810.

[12] Hayat T., Qayyum S., Alsaedi A. and Waqas M. (2016): Simultaneous influences of mixed convection and nonlinear thermal radiation in stagnation point flow of Oldroyd-B fluid towards an unsteady convectively heated stretched surface.- Journal of Molecular Liquids, vol.224, pp.811-817. 
[13] Hayat T., Waqas M., Alsaedi A., Bashir G. and Alzahrani F. (2017): Magnetohydrodynamic (MHD) stretched flow of tangent hyperbolic nanoliquid with variable thickness.- Journal of Molecular Liquids, vol.229, pp.178-184.

[14] Hayat T., Zubair M., Waqas M., Alsaedi A. and Ayub M. (2017): On doubly stratified chemically reactive flow of Powell-Eyring liquid subject to non-Fourier heat flux theory. - Results in Physics,vol.7, pp.99-106.

[15] Hayat T., Khalid H., Waqas M. and Alsaedi A. (2018): Numerical simulation for radiative flow of nanoliquid by rotating disk with carbon nanotubes and partial slip. - Computer Methods in Applied Mechanics and Engineering,vol.341,pp.397-408.

[16] Asghar Z., Ali N., Ahmed R., Waqas M. and Khan W.A. (2019): A mathematical framework for peristaltic flow analysis of non-Newtonian Sisko fluid in an undulating porous curved channel with heat and mass transfer effects. - Computer Methods and Programs in Biomedicine, vol.182, 105040.

[17] Waqas M., Shehzad S.A., Hayat T., Khan M.I. and Alsaedi A. (2019): Simulation of magnetohydrodynamics and radiative heat transport in convectively heated stratified flow of Jeffrey nanofluid.- Journal of Physics and Chemistry of Solids, vol.133, pp.45-51.

[18] Waqas M., Jabeen S., Hayat T., Khan M.I. and Alsaedi A. (2019): Modeling and analysis for magnetic dipole impact in nonlinear thermally radiating Carreau nanofluid flow subject to heat generation. - Journal ofMagnetism and Magnetic Materials, vol.485, pp.197-204.

[19] Waqas M., Hayat T. and Alsaedi A. (2019): A theoretical analysis of SWCNT-MWCNT and $\mathrm{H}_{2} \mathrm{O}$ nanofluids considering Darcy-Forchheimer relation. - Applied Nanoscience, vol.9, pp.1183-1191.

[20] Waqas M. (2020): A mathematical and computational framework for heat transfer analysis of ferromagnetic nonNewtonian liquid subjected to heterogeneous and homogeneous reactions. - Journal of Magnetism and Magnetic Materials, vol.493, 165646.

[21] Waqas M., Khan M.I., Hayat T., Gulzar M.M. and Alsaedi A. (2020): Transportation of radiative energy in viscoelastic nanofluid considering buoyancy forces and convective conditions. - Chaos, Solitons and Fractals, vol.130, 109415.

[22] Dogonchi A.S., Waqas M. and Ganji D.D. (2019): Shape effects of Copper-Oxide (CuO) nanoparticles to determine the heat transfer filled in a partially heated rhombus enclosure: CVFEM approach.- International Communications in Heat and Mass Transfer, vol.107, pp.14-23.

[23] Farooq S., Khan M.I., Waqas M., Hayat T. and Alsaedi A. (2020): Transport of hybrid type nanomaterials in peristaltic activity of viscous fluid considering nonlinear radiation, entropy optimization and slip effects. Computer Methods and Programs in Biomedicine, vol.184, 105086.

Received: November 6, 2019

Revised: December 26, 2019 